\title{
APUNTES SOBRE EL SISTEMA ELECTORAL PROVINCIAL
}

\author{
Carlos Garrido López \\ Profesor Titular de Derecho Constitucional, \\ Universidad de Zaragoza
}

Cómo citar este artículo / Citation: Garrido López, C. (2021).

Apuntes sobre el sistema electoral provincial.

Palacios Romeo, F. y Cebrián Zazurca, E. (coords.)

Elección y representación: una conjunción compleja. Perspectivas y problemas de los regímenes electorales en España, Colección Obras colectivas, Fundación Manuel Giménez Abad, Zaragoza.

DOI: https://doi.org/10.47919/FMGA.OC21.0309

SUMARIO: I. REPRESENTATIVIDAD Y SISTEMA ELECTORAL DE LAS DIPUTACIONES PROVINCIALES - II. EL REPARTO DE LOS ESCAÑOS DE DIPUTADO ASIGNADOS A LA DIPUTACIÓN ENTRE LOS PARTIDOS JUDICIALES DE LA PROVINCIA - III. LA ELABORACIÓN DE UNA RELACIÓN DE TODOS LOS PARTIDOS, COALICIONES, FEDERACIONES Y DE CADA UNA DE LAS AGRUPACIONES DE ELECTORES QUE HAYAN OBTENIDO CONCEJALES EN LA CIRCUNSCRIPCIÓN - IV. LA DISTRIBUCIÓN DE LOS PUESTOS DE DIPUTADO ENTRE LAS FORMACIONES POLÍTICAS Y CADA UNA DE LAS AGRUPACIONES DE ELECTORES ATENDIENDO A LOS VOTOS OBTENIDOS EN EL PROCESO ELECTORAL A QUO - V. LA ELECCIÓN, POR LOS CONCEJALES DE CADA ENTIDAD POLÍTICA Y DE ENTRE ELLOS, DE LOS DIPUTADOS PROVINCIALES QUE CORRESPONDEN EN LA CIRCUNSCRIPCIÓN A CADA PARTIDO POLÍTICO, COALICIÓN, FEDERACIÓN O AGRUPACIÓN DE ELECTORES 


\section{REPRESENTATIVIDAD Y SISTEMA ELECTORAL DE LAS DIPUTACIONES PROVINCIALES}

El artículo 141.2 de la Constitución (CE) encomienda el gobierno y la administración de la provincia "a las diputaciones provinciales u otras corporaciones de carácter representativo", pero no menciona ninguna modalidad electoral concreta para dotar a dichas corporaciones de representatividad política, a diferencia del artículo 140 de la CE relativo a los órganos de gobierno de los municipios, que prevé la elección de sus miembros por los vecinos mediante sufragio universal, igual, libre, directo y secreto. Esta apertura en relación con las diputaciones u otras corporaciones representativas provinciales parecía dejar un amplio espacio al legislador para determinar el sistema electoral que les proporcionara legitimidad conforme al principio democrático.

A juicio de alguna doctrina, la mención constitucional a la provincia como entidad local "determinada por la agrupación de municipios" y el hecho de que sus competencias fueran fundamentalmente instrumentales, de coordinación y asistencia a los municipios, justificaban la opción por un sistema electoral de segundo grado que trasladara a la diputación una representatividad municipal. La naturaleza y la función de la provincia avalaban, según esta interpretación, la fórmula adoptada en la Ley 39/1978, de 17 de julio, de Elecciones Locales (LEL), y más tarde, con ligeras modificaciones, en la Ley Orgánica 5/1985, de 19 de junio, del Régimen Electoral General (LOREG), en virtud de la cual los diputados provinciales no incorporan una representatividad popular directa, sino indirecta, a través de su elección por los concejales de los municipios integrados en la provincia que actúan, de este modo, como instrumentos de mediación entre la entidad provincial y su población ${ }^{1}$. El Tribunal Constitucional (TC), sin embargo, no ratificó esa tesis. En la STC 38/1983, de 16 de mayo, señaló que la referencia a la provincia como entidad "determinada por la agrupación de municipios" podía ser considerada, por recurrente en nuestro

\footnotetext{
${ }^{1}$ En este sentido, L. COSCULLUELA MONTANER y S. MUÑOZ MACHADO, Las elecciones locales, Abella, Madrid, 1979, pp. 326-327; L. COSCULLUELA MONTANER, "Las elecciones locales", en S. MUÑOZ MACHADO (dir.), Tratado de derecho municipal, Civitas, Madrid, 1988, pp. 690-691, J. SUAY RINCÓN, "Especificidades de las diputaciones provinciales y cabildos insulares", en Elecciones locales, Instituto Nacional de Administración Pública, Madrid, 1998, pp. 208-209, y M. SALVADOR CRESPO, La autonomía provincial en el sistema constitucional español. Intermunicipalidad y Estado autonómico, INAP-Fundación Democracia y Gobierno Local, Madrid, p. 145.
} 
derecho histórico, mera inercia legislativa o incluso entenderse "como simple alusión a una base física, geográfica o territorial, expresión sustitutoria o equivalente a una descripción jurídica, sin más alcance que el anotado" (fundamento jurídico 6), por lo que no cabía extraer de ella conclusiones sobre el sistema electoral provincial más idóneo. En la STC 103/2013, de 25 de abril, reconoció al legislador una amplia libertad a la hora de configurar la forma de gobierno de las provincias, dado que el principio representativo tiene, en el caso de las diputaciones provinciales, "una menor densidad normativa que la que corresponde a los municipios" (fundamento jurídico 6). Y en la STC 111/2016, de 9 de junio, tras considerar el sistema electoral de segundo grado de las diputaciones configurado por el legislador compatible con el principio democrático, constató "que la Constitución, a la vez que garantiza la autonomía de la provincia (art. 141.1 de la CE), exigiendo del legislador las intervenciones que la materialicen, deja deliberadamente abierto el tipo de legitimidad (directa o indirecta) que exige su carácter representativo (art. 141.2 de la CE)" (fundamento jurídico 9).

En un Estado democrático, representar exige dotar de representatividad política. La forma de composición de los órganos representativos no resulta, por tanto, irrelevante. Dicha forma debe ser electiva y capaz de trasladar a la diputación provincial el pluralismo político de la comunidad representada. Pero más allá de estas exigencias del principio democrático, el legislador orgánico es libre para configurar el concreto modelo de legitimación democrática de los órganos de gobierno y administración de las provincias. $\mathrm{Y}$, de hecho, adoptando una fórmula electoral más o menos proporcional en relación con la población residente en la provincia ${ }^{2}$, casi todos los modelos de elección fueron propuestos durante la primera etapa de nuestro régimen constitucional, desde la elección directa de los diputados provinciales por los ciudadanos de la provincia a la elección indirecta de segundo grado por los concejales, pasando

\footnotetext{
${ }^{2}$ A juicio de alguna doctrina, la condición representativa de las diputaciones provinciales consagrada en el 141.2 fuerza "a ser coherentes con el mecanismo de designación que la acompaña y, si este gira en torno a los concejales elegidos en todos los municipios de la provincia -los cuales han de nombrar a los diputados provinciales-, sólo la proporcionalidad será capaz de reflejar la voluntad política, mediatamente expresada, de los representados". Cfr. L. Ma. DíEZ-PICAZO, "Los «criterios de representación proporcional» del artículo 68.3 de la Constitución: su alcance y proyección a efectos distintos de la elección para el Congreso de los Diputados", en VVAA, Estudios sobre la Constitución Española. Homenaje al profesor E. García de Enterría, tomo III, Civitas, Madrid, 1991, p. 2068.
} 
por sistemas mixtos con existencia de dos tipos de diputados que acceden a la diputación por diferentes vías.

La elección directa de los diputados provinciales en circunscripciones plurinominales fue prevista en el proyecto de ley orgánica por el que se regulan las elecciones para las diputaciones provinciales, elaborado por el Gobierno de Calvo Sotelo en cumplimiento de los pactos autonómicos suscritos en 1981 entre el Gobierno de Unión de Centro Democrático (UCD) y el Partido Socialista Obrero Español (PSOE), pero dicho proyecto decayó ${ }^{3}$. Durante la tramitación de la LEL en marzo de 1978, el grupo parlamentario socialista propuso, por su parte, para las diputaciones provinciales un sistema de elección mixto que permitiera la existencia simultánea de diputados elegidos directamente en circunscripción única y diputados designados por los concejales en cada partido judicial ${ }^{4}$. Años después, durante la tramitación de la LOREG, varias enmiendas de diputados comunistas postularon la adopción de un sistema electoral de segundo grado en circunscripción única coincidente con la totalidad del territorial provincial ${ }^{5}$. Siguiendo la fórmula más arraigada en nuestro derecho local y en consonancia con la concepción instrumental de la

${ }^{3}$ El proyecto de ley orgánica puede verse en el Boletín Oficial de las Cortes Generales, Serie A, núm. 271-I, 13 de mayo de 1982, pp. 2023-2024. La disolución de las cámaras y la victoria electoral del PSOE supuso el abandono de dicho proyecto, pero la elección directa se abrió paso en el País Vasco, cuyas Leyes 2, 3 y 4, de 7 de marzo de 1983, la establecieron para las juntas generales de los territorios históricos (regulada en la actualidad en la Ley 1/1987, de 27 de marzo, de elecciones para las juntas generales de los territorios históricos de Araba, Bizkaia y Guipuzcoa, modificada por Ley 5/1993, de 16 de julio, y Ley 4/2005, de 28 de febrero), y también en Canarias, aunque no referida a las mancomunidades interinsulares, réplica meramente formal de las diputaciones provinciales en el archipiélago, sino a los cabildos insulares, cuyo sistema electoral directo, regulado en el artículo 201 de la LOREG, trae causa del artículo 37 de la LEL. Y, hasta la entrada en vigor del Estatuto de Autonomía de las Islas Baleares, también los miembros de los consejos insulares se elegían directamente por los ciudadanos, de conformidad con el artículo 39 de la LEL. Sobre las diputaciones forales y los cabildos y consejos en Canarias y Baleares, respectivamente, M. SALVADOR CRESPO, EI gobierno local en España, Marcial Pons, Madrid, 2019, pp. 123-135.

${ }^{4}$ En este sentido, la enmienda núm. 66 al título IV del proyecto de LEL, defendida tanto en Comisión (Diario de Sesiones del Congreso, Comisión de Interior, núm. 27, de 2 de marzo de 1978, p. 21) como en el Pleno (Diario de Sesiones del Congreso, Pleno, núm. 29, de 9 y 10 de marzo de 1978, pp. 1138-1139). Idéntica fórmula propugnaron sin éxito los diputados comunistas durante la tramitación parlamentaria de la Ley Orgánica 6/1983, de 2 de marzo, de reforma de la LEL a través de la enmienda núm. 34 al artículo 5 del proyecto de reforma, defendida en Comisión (Diario de Sesiones del Congreso de los Diputados, II Legislatura, Comisión de Régimen de las Administraciones Públicas, núm. 4, de 3 de febrero de 1983, pp. 167-168).

${ }^{5}$ Véanse las enmiendas núms. 363 y 444 presentadas al proyecto de ley en Ley Orgánica de Régimen Electoral General. Trabajos Parlamentarios, tomo I, Cortes Generales, Madrid, 1986, pp. 288 y 304-305, respectivamente, con las que se pretendía, al apostar por la circunscripción provincial única, potenciar la proporcionalidad en el reparto de escaños en la diputación. 
provincia anteriormente citada, el legislador de la LEL y, después, el de la LOREG, optaron, sin embargo, por combinar la elección indirecta de segundo grado de los diputados provinciales por los concejales en los partidos judiciales de la provincia con diversas fórmulas automáticas de reparto de los escaños a partir del número de votos obtenido por las formaciones políticas en las elecciones municipales ${ }^{6}$. $Y$ desde su adopción, pese a las críticas que ha recibido por "indirecto, partidista, mayoritario, complejo y opaco" ${ }^{7}$, este sistema continúa siendo la fórmula usada para conferir representatividad a las diputaciones provinciales; una fórmula sin viso alguno de modificación debido a la cómoda posición dominante que otorga a los principales partidos políticos.

El sistema electoral de las diputaciones provinciales adoptado y mantenido por el legislador, en contra incluso del artículo 3.2 de la Carta Europea de Autonomía Local $^{8}$, supone la combinación de dos procedimientos complementarios: de una parte, la elección indirecta de los diputados, atribuida, en cuanto portadores del vínculo que une a la entidad con su población, a los concejales de los municipios comprendidos en las circunscripciones electorales en que se divide la provincia, pero no a todos los concejales, sino sólo a los

\footnotetext{
${ }^{6}$ El resultado de esta opción, prevista en la LEL y mantenida con ligeras variantes en su reforma de 1983 y, más tarde, en los artículos 204 a 206 de la LOREG, no constituye una elección indirecta o en pirámide en sentido estricto, sino, como subrayó I. ASTARLOA HUARTE-MENDICOA, un procedimiento electoral intermedio en el que los ciudadanos no eligen a los diputados, pero en el que tampoco los concejales actúan como compromisarios incondicionados en los distritos en que se divide electoralmente la provincia. Cfr. "Comentario al artículo 205", en L. Ma. CAZORLA PRIETO (dir.), Comentarios a la Ley Orgánica del Régimen Electoral General, Civitas, Madrid, 1988, p.1786.

${ }^{7}$ C. A. FOGUET, "Breve manual de supervivencia al sistema electoral provincial", Politikon, 24 de septiembre de 2012 (disponible en: https://politikon.es/2012/09/24/breve-manual-desupervivencia-al-sistema-electoral-provincial/). Una síntesis de las principales críticas y de las propuestas de reforma que, ante la indiferencia de los partidos políticos, se han formulado en los últimos años pueden verse en Libro Verde. Los gobiernos locales intermedios en España. Diagnóstico y propuestas para reforzar el valor institucional de las diputaciones provinciales y de los demás gobiernos locales intermedios en el Estado autonómico, Fundación Democracia y Gobierno Local, Madrid, 2011, p. 83 (disponible en http://repositorio.gobiernolocal.es/xmlui/handle/10873/772) y P. BIGLINO CAMPOS, "La reforma de la elección de los miembros de las diputaciones provinciales: mejorar la legitimidad de origen respetando la legitimidad de ejercicio", en L. J. PAREJO ALFONSO (dir.), El futuro de la Administración local y el papel de los gobiernos locales intermedios, Fundación Democracia y Gobierno Local, Barcelona, 2017, pp. 364-366.

${ }^{8}$ Según el artículo 3.2 de la Carta Europea de Autonomía Local, hecha en Estrasburgo el 25 de octubre de 1985, la autonomía local "se ejerce por asambleas y consejos integrados por miembros elegidos por sufragio libre, secreto, igual, directo y universal". Debido a su tenor literal, España tuvo que introducir una reserva en el instrumento de ratificación de la Carta a fin de excluir su aplicación al sistema electoral indirecto de las diputaciones provinciales. Cfr. Instrumento de ratificación de la Carta Europea de Autonomía Local, BOE, núm. 47, de 24 de febrero de 1989, p. 5396.
} 
que pertenecen a las formaciones políticas o agrupaciones de electores que han obtenido escaños en la diputación. De otra parte, y con carácter previo a dicha elección, la determinación automática del número de escaños que corresponden, primero, a cada circunscripción en función de su población residente y, segundo, a cada uno de las formaciones políticas o agrupaciones de electores que concurrieron a las elecciones municipales en función del número de votos alcanzado en la respectiva circunscripción ${ }^{9}$. Se corrige, así, mediante la asignación matemática del número de puestos correspondientes a cada grupo político o agrupación de electores, la desproporción entre escaños y votos que se derivaría de un mecanismo indirecto stricto sensu en el que los concejales electos de cada distrito pudieran actuar incondicionalmente como compromisarios, lo que es coherente con la consideración de la provincia como expresión jurídica de una colectividad integrada por los ciudadanos que residen en ella ${ }^{10}$. El legislador ha introducido, no obstante, importantes correctivos a la proporcionalidad que se hacen presentes a lo largo del proceso.

En este trabajo expondré las razones de la opción en favor de este sistema electoral y analizaré las fases en que dicho sistema se divide, desde la distribución por las juntas electorales provinciales del número de diputados que se atribuyen a la diputación entre las circunscripciones electorales de la provincia, hasta la elección, ante las juntas electorales de zona, por los concejales de cada entidad política y entre sí, de los diputados correspondientes a las diversas formaciones políticas y las agrupaciones de electores que han obtenido escaños en cada circunscripción.

\section{EL REPARTO DE LOS ESCAÑOS DE DIPUTADO ASIGNADOS A LA DIPUTACIÓN ENTRE LOS PARTIDOS JUDICIALES DE LA PROVINCIA}

Determinada la dimensión de las diputaciones provinciales conforme al baremo poblacional establecido en el artículo 204.1 de la LOREG $^{11}$, las juntas

\footnotetext{
${ }_{9}^{9}$ M. SALVADOR CRESPO, El gobierno local en España, cit., pp. 112-113.

${ }^{10}$ Sobre la naturaleza de la provincia como entidad local, L. MORELL OCAÑA, El régimen local español, tomo I, Civitas, Madrid, 1988, pp. 767-768 y M. SALVADOR CRESPO, La autonomía provincial en el sistema constitucional español. Intermunicipalidad y Estado autonómico, cit., pp. 135-136.

${ }^{1}$ Con una población provincial de hasta 500.000 residentes, el artículo 204.1 de la LOREG atribuye a las diputaciones provinciales veinticinco diputados; con una población de 500.001 a un millón de residentes, asigna veintisiete diputados; con una población de un millón a tres 
electorales provinciales proceden a repartir, "proporcionalmente y atendiendo al número de residentes", los puestos de diputados que corresponderán a cada una de las circunscripciones electorales en que se divide la provincia (art. 204.2 de la LOREG). Dicha operación se realiza el décimo día después de la convocatoria de las elecciones municipales. Y la circunscripción electoral elegida a estos efectos es el partido judicial, que el artículo 32 de la Ley Orgánica 6/1985, de 1 de julio, del Poder Judicial (LOPJ) define como la unidad territorial para la administración de justicia integrada por uno o más municipios pertenecientes a la misma provincia, pero sin conferirle funcionalidad electoral alguna. Esta peculiar circunscripción, que no se prevé para el resto de procesos electorales, cuenta con una larga tradición en nuestro derecho local como demarcación para la atribución de los puestos de diputado provincial ${ }^{12}$. Alguna doctrina ha sostenido que su utilización como circunscripción en la LEL y su mantenimiento en la LOREG pretendía evitar el gerrymandering y garantizar en la diputación provincial una presencia equilibrada de diputados designados en zonas rurales y en zonas urbanas, mucho más pobladas ${ }^{13}$. No creemos, sin embargo, que la opción en favor del partido judicial como demarcación electoral se deba a ello, sino al peso de la tradición y a la constatación de que los partidos eran, a la sazón, las únicas divisiones territoriales formadas por municipios de una misma provincia y de que, con su adopción, "se evitaba tener que hacer nuevas divisiones, con los problemas que ello comportaba" 14 .

A fin de evitar los conflictos interpretativos suscitados tras la aprobación de la LEL de 1978, que aludía genéricamente a los partidos judiciales sin ulterior concreción -lo que suscitó en 1979 una seria disparidad de criterios entre las juntas electorales provinciales y la Junta Electoral Central (JEC) sobre cuáles

millones y medio de residentes, treinta y un diputados; y a partir de tres millones y medio de residentes, cincuenta y un diputados provinciales.

${ }^{12}$ La asignación de esta función a los partidos judiciales se remonta al Real Decreto de 21 de septiembre de 1935, al que siguió la Ley de Diputaciones de 8 de enero de 1845 y la Ley Provincial de 25 de septiembre de 1863. La Ley Provincial de 20 de agosto de 1870 optó por distritos electorales fijados por el Gobierno, aunque recomendando a este que respetase los partidos judiciales. La Ley de 29 de agosto de 1882 agrupó los partidos judiciales de dos en dos, asignando a cada agrupación cuatro diputados y fijando en cada provincia un mínimo de cinco distritos. Sólo el Estatuto Provincial 21 de marzo de 1925 abandonó los partidos judiciales, optando por la circunscripción provincial única, con excepción de las Islas Baleares y de las capitales que tuvieran más población que el resto de la provincia (arts. 54 y 55).

${ }^{13}$ B. PENDÁS GARCÍA, "El sistema electoral en las elecciones locales", en VV.AA. Reflexiones sobre el régimen electoral, IV Jornadas de Derecho Parlamentario, Congreso de los Diputados, Madrid, 1997, p. 575.

${ }^{14}$ C. A. FOGUET, "Breve manual de supervivencia al sistema electoral provincial", cit. 
debían ser los partidos judiciales a tener en cuenta, si los trazados en el Decreto 3388/1965, de 11 de noviembre, o los establecidos en el mapa precedente, recogido en una Orden Ministerial de 24 de marzo de $1945^{15}$-, el legislador, en el apartado 3 del artículo 204 de la LOREG, señaló que los partidos judiciales a los efectos del procedimiento electoral de las diputaciones provinciales coinciden con las elecciones locales de 1979. Dichos partidos han quedado así congelados en el tiempo, de suerte que no pueden ser otros que los enumerados en el Anexo del Real Decreto 529/1983, de 9 de marzo, por el que se determinan los partidos judiciales de cada provincia a considerar a efectos de las elecciones de diputados provinciales, y, consecuentemente, los creados desde entonces, fundamentalmente en la Ley 38/1988, de 28 de diciembre, de Demarcación y Planta Judicial, no constituyen circunscripciones electorales ${ }^{16}$.

Además de la citada congelación, el problema de la utilización de los partidos judiciales como circunscripciones es que, dado su elevado número, que en la mayoría de los casos determina un reducido tamaño electoral, no propician la proporcionalidad del sistema electoral. Los partidos judiciales, y menos si se

\footnotetext{
${ }^{15}$ El Real Decreto 34/1979, de 5 de enero, por el que se dictaron normas para la determinación del número de componentes a elegir para cada una de las corporaciones locales, subrayó que el último trazado de los partidos judiciales correspondía al Decreto 3388/1965, de 11 de noviembre, pero, como el artículo 8 de este señalaba que las modificaciones que introducía en el trazado anterior quedaban limitadas "al ámbito estrictamente judicial, sin que, por tanto, impliquen alteraciones en las restantes demarcaciones de índole hipotecaria, administrativa, recaudatoria, electoral o de cualquier otra naturaleza" (subrayado nuestro), la JEC consideró, en sus resoluciones de 14 y 21 de febrero de 1979 y de 20 de diciembre de 1982, que el mapa de partidos judiciales aplicable a efectos electorales debía ser el recogido, básicamente, en la Orden Ministerial de 24 de marzo de 1945, que incluía muchos más partidos que el mapa previsto en el Real Decreto de 1965. Los problemas interpretativos acerca de la norma aplicable en punto al trazado de los partidos judiciales con anterioridad a la "congelación" operada por el artículo 204.5 LOREG y su impacto sobre la proporcionalidad del reparto de escaños en la diputación fueron analizados por B. FERNÁNDEZ PÉREZ, "Las referencias a la demarcación judicial en la Ley de Elecciones Locales", Revista de Estudios Políticos, núm. 10, 1979, pp. 132-135.

${ }^{16}$ La disposición adicional $1^{\text {a }}$ de la LOPJ, coetánea a la LOREG, exigía al Gobierno la remisión en plazo perentorio a las Cortes Generales de un proyecto de ley de planta y demarcación judicial, cuya aprobación actualizaría y, en su caso, modificaría los partidos judiciales existentes. Resultaba, por ello, sorprendente que la LOREG mantuviera "anticuados y desfasados morfismos cuando la propia organización judicial era consciente de la distinta funcionalidad de su estructura organizativa en relación con las estructuras administrativas" y cuando, en su práctica operativa, mostraba "un acusado respeto a la autonomía municipal, hasta el extremo de reformar su estructura territorial en función de los cambios en la estructura espacial de los términos municipales". Cfr. A. SÁNCHEZ BLANCO, "La ley electoral como instrumento de articulación institucional: la estructura organizativa y el procedimiento electoral de las diputaciones provinciales", Revista de Administración Pública, núm. 108, 1985, pp. 9394.
} 
tienen en cuenta los que ya no existen, no son demarcaciones que se ajusten realmente al asentamiento de la población en el territorio, lo que provoca una distorsión significativa en el reparto de escaños. Y como en la mayoría de ellos sólo se eligen de uno a tres representantes provinciales ${ }^{17}$, la fórmula proporcional D'Hondt a la que, como veremos, el artículo 205.3 de la LOREG remite a las juntas electores de zona para distribuir los escaños entre los grupos políticos y las agrupaciones de electores, opera, en la práctica, como una fórmula mayoritaria, lo que reduce el pluralismo político en la diputación y excluye a los partidos minoritarios del reparto de escaños de un modo más efectivo que los umbrales mínimos previstos en la LOREG para otros procesos electorales ${ }^{18}$.

A este efecto contribuyen las previsiones del apartado 2 del artículo 204 de la LOREG, cuyas letras a) y b) establecen dos correctivos a la regla de la proporcionalidad aplicable al reparto de escaños que el apartado 1 del mismo artículo encomienda a las juntas electorales provinciales: el primero, que todos los partidos judiciales deberán contar, al menos, con un diputado provincial; y el segundo, que a ningún partido judicial puede asignársele más de tres quintos del número total de diputados provinciales. Como los acuerdos de la JEC de 17 de junio de 1987 y de 13 de mayo de 1999 subrayaron, la asignación de un diputado como mínimo no implica, como en la vieja LEL, que cada circunscripción tenga un diputado más el o los que le correspondan en el reparto proporcional de la población, sino que cada circunscripción dispone de los diputados provinciales que resulten de la proporción poblacional con un mínimo de uno, lo que constituye una garantía para aquellos partidos judiciales

\footnotetext{
${ }^{17}$ En sesenta partidos judiciales de los enumerados en el Anexo del Real Decreto 529/1983, de 9 de marzo, por el que se determinan los partidos judiciales de cada provincia a considerar a efectos de las elecciones de diputados provinciales, se elige un único diputado; en cincuenta y seis partidos judiciales, se eligen dos diputados, y en otros cuarenta y seis partidos judiciales, tres diputados. En más de la mitad de las circunscripciones incluidas en el Anexo citado, por tanto, el sistema electoral provincial opera de facto como mayoritario, por más que el artículo 205.3 de la LOREG prevea, mediante reenvío al artículo 163 de la LOREG, la aplicación de la regla proporcional D'Hondt para distribuir los escaños entre los partidos, coaliciones, federaciones y agrupaciones de electorales en cada partido judicial según el número de votos obtenidos por ellos en las elecciones municipales. Cfr. Libro Verde, Los gobiernos locales intermedios en España. Diagnóstico y propuestas para reforzar el valor institucional de las diputaciones provinciales y de los demás gobiernos locales intermedios en el Estado autonómico, Fundación Democracia y Gobierno Local, Madrid, 2011, p. 82.

${ }^{18}$ En este sentido, P. BIGLINO CAMPOS, "La reforma de la elección de los miembros de las diputaciones provinciales: mejorar la legitimidad de origen respetando la legitimidad de ejercicio", cit., pp. 365-366; J. Mª. SABATÉ VIDAL, "Comicios locales y diputaciones provinciales", El Consultor de los Ayuntamientos, núm. 2, Abril 2019, pp. 167-168.
} 
que, debido a su baja demografía, quedarían de otro modo sin escaño. Por su parte, la asignación de un máximo supone que, independientemente de los diputados que corresponderían proporcionalmente al partido judicial más poblado, dicho partido no puede obtener en el reparto más de tres quintos del total, como subrayó el acuerdo de la JEC de 3 de junio de 1999 al negar la asignación de 19 diputados al partido judicial de Sevilla, siendo 31 los atribuidos a la diputación. Ambas reglas pretenden paliar los efectos representativos de la desigualdad demográfica provincial, asegurando una representación mínima de las circunscripciones más despobladas y limitando la sobrerrepresentación de la capital de la provincia, que, de otro modo, debido a su peso poblacional, acapararía la práctica totalidad de los escaños de la diputación.

Conviene recordar a este respecto que la LEL fijaba como límite máximo la asignación de un tercio de los diputados en lugar de los tres quintos previstos en la LOREG, lo que otorgaba una prima mayor a las zonas rurales. Este cambio supuso un avance en favor de la representación de la provincia concebida como colectividad frente a los municipios que la integran, pero alguna doctrina ha sido muy crítica con el nuevo límite por, en su opinión, "la desproporcionada representación en las diputaciones, por excesiva, de las capitales" en detrimento de "la representación auténticamente provincial" correspondiente a los municipios ${ }^{19}$. No suscribimos, sin embargo, dicha crítica, porque, citando las palabras de Morell Ocaña, "si se está ordenando el sufragio aunque sea indirecto a base de una pluralidad de circunscripciones, no puede soslayarse la distribución sobre las mismas de la población representada. [...]. En ese sentido se orienta la $L O R E G^{\prime 20}$, que introduce, no obstante, correctivos a la proporcionalidad a fin de lograr un mínimo equilibrio representativo entre los diferentes territorios de la provincia, pero teniendo en cuenta que el sujeto representado no son los municipios, sino la colectividad integrada por los ciudadanos residentes en la provincia.

La letra c) del artículo 204 de la LOREG incorpora, por su parte, el criterio del redondeo aplicable a los supuestos en los que la distribución de diputados

\footnotetext{
${ }^{19}$ S. MARTÍN-RETORTILLO BAQUER, "Presente y futuro de las diputaciones provinciales", en R. GÓMEZ-FERRER MORANT (coord.), La provincia. Pasado, presente y futuro, Civitas, Madrid, 1991, pp. 76-77. En el mismo sentido, L. COSCULLUELA MONTANER, "Las elecciones locales", cit., pp. 727-728.

${ }^{20}$ MORELL OCAÑA, L. El régimen local español cit. p. 767. 
provinciales atendiendo al número de residentes por circunscripción no dé como resultado números enteros. En esos casos, las fracciones iguales o superiores a 0,50 que resulten del reparto proporcional deben corregirse por exceso y las inferiores por defecto ${ }^{21}$. $Y$ ante la eventualidad de que, tras estas operaciones, resultase un número total de diputados que no coincidiera, por exceso, con el asignado a la provincia, la junta electoral correspondiente debe sustraer los puestos necesarios a las circunscripciones electorales cuya relación entre residentes y diputados sea menor. $\mathrm{Y}$, al contrario, de no coincidir el número por defecto, la junta electoral debe añadir puestos a las circunscripciones en que dicha relación fuera mayor. De este modo se consigue, en caso de exceso, aumentar el ratio indicado y, en caso de defecto, reducirlo, logrando mayor homogeneidad entre el número de residentes por diputado en cada circunscripción. A tal efecto, las juntas electorales deben dividir la población de cada uno de los partidos judiciales, menos el que haya alcanzado el número máximo de puestos que cabe atribuir según la letra b) del artículo 204.2 de la LOREG, por números sucesivos para determinar el mejor cociente que permita la asignación de cada uno de los puestos por el número de diputados ya asignados al partido judicial más uno, aplicando analógicamente la regla y el ejemplo contenidos en el artículo 163.1.c) de la LOREG (acuerdo de la JEC de 13 de mayo de 1999). O lo que es lo mismo, en el caso de no coincidencia por defecto, dividiendo los residentes por una serie 1,2 , 3, etc., y otorgando un diputado provincial al partido judicial que, aplicando la regla del artículo 204.2.d) de la LOREG en el sentido apuntado, tenga mayor número de residentes por diputado provincial, como subrayó el acuerdo de la JEC de 10 de junio de 1999. O a la inversa, en caso de no coincidir por exceso, restando el diputado provincial a los partidos cuya ratio de residentes por diputado sea menor.

\footnotetext{
${ }^{21}$ Al cociente de 2,49 del partido judicial de Tui (provincia de Pontevedra) en las elecciones locales de 2007 le correspondieron, por ello, dos diputados, rechazándose la aplicación de otras reglas, como que las fracciones se calcularan a dos decimales o que pudiera aplicarse analógicamente la Ley 46/1998, de 17 de diciembre, sobre introducción del euro. Acuerdo de la JEC de 23 de abril de 2007.
} 
III. LA ELABORACIÓN DE UNA RELACIÓN DE TODOS LOS PARTIDOS, COALICIONES, FEDERACIONES Y DE CADA UNA DE LAS AGRUPACIONES DE ELECTORES QUE HAYAN OBTENIDO CONCEJALES EN LA CIRCUNSCRIPCIÓN

Celebradas las elecciones municipales y constituidos los ayuntamientos de la provincia, comienza el proceso electoral propiamente dicho, cuyas diversas fases se caracterizan por un inusitado protagonismo otorgado a los partidos políticos. En una primera fase, regulada en el artículo 205 de la LOREG, las juntas electorales de zona proceden a formar una relación de las formaciones políticas y de cada una de las agrupaciones de electores que hayan obtenido algún concejal en la circunscripción y, tras ello, reparten los escaños que correspondan a dichas formaciones y agrupaciones conforme a la regla D'Hondt aplicada sobre los resultados del proceso electoral a quo. En una segunda fase, las juntas electorales de zona convocan a los concejales de las formaciones políticas o agrupaciones de electores "que hayan obtenido puestos de diputado" para que, en colegios separados y en una suerte de contienda electoral interna si concurren varias listas, elijan de entre ellos a quienes han de ser proclamados diputados provinciales, según prevé el artículo 206 de la LOREG.

Satisfecha la exigencia de constitución previa de los ayuntamientos prevista en el artículo 205.1 de la LOREG para activar el procedimiento, con las excepciones allí citadas ${ }^{22}$, las juntas electorales de zona proceden a elaborar en su partido judicial una relación de todos los partidos políticos, coaliciones y

\footnotetext{
${ }^{22}$ La Ley Orgánica 2/2011, de 28 de enero, modificó la LOREG añadiendo al artículo 205.1 dos nuevos párrafos. En el primero, el legislador ha confirmado que el proceso electoral de las diputaciones provinciales debe aplazarse hasta que se hayan resuelto todos los recursos contencioso-electorales presentados contra la proclamación de concejales electos en los municipios de la provincia y, consecuentemente, se hayan constituido sus ayuntamientos, conforme a la exigencia con la que principia el propio artículo 205.1 de la LOREG. En el segundo, sin embargo, se establece que dicho proceso electoral no se pospondrá a la constitución de todos los ayuntamientos "en el caso de que deban convocarse nuevas elecciones en algún municipio de la provincia, bien por no haberse presentado ninguna candidatura, bien por haberse anulado total o parcialmente el proceso como consecuencia de los correspondientes recursos contenciosos-electorales". No obstante, si como consecuencia de la celebración de elecciones locales parciales se altera la atribución de puestos en la diputación -esto es, el reparto de escaños entre las formaciones políticas-, las juntas electorales de zona deberán realizar las operaciones necesarias para efectuar una nueva asignación y, consecuentemente, proceder a la repetición de las elecciones provinciales en el partido judicial correspondiente. Una crítica a esta reforma de la LOREG en F. CACHARRO GOSENDE, "La nueva redacción del artículo 205.1 de la Ley orgánica del régimen electoral general: una reforma inconstitucional", Cuadernos de derecho local, núm. 26, 2011, pp. 48-52.
} 
federaciones y de cada una de las agrupaciones de electores que hayan logrado, al menos, un concejal en el distrito, ordenándolos en orden decreciente al de los votos obtenidos por cada uno de ellos en las elecciones municipales $^{23}$. A estos efectos, lo relevante para el legislador es poder configurar una prelación entre las formaciones políticas, y no quién ha sido el destinatario formal de los votos populares, como refleja la fórmula prevista en el apartado 2 del artículo 205 de la LOREG para imputar votos a dichas formaciones en el caso de los municipios con una población entre 100 y 250 habitantes. En estos municipios, muy numerosos en España a causa de la baja demografía de extensas áreas rurales del interior peninsular, los vecinos votan a candidatos individuales en listas abiertas, conforme al sistema electoral mayoritario establecido en el artículo 184 de la LOREG. Pero ello no impide, a efectos del cómputo diseñado en el procedimiento electoral provincial, sumar a los partidos, coaliciones o federaciones que postularon a dichos candidatos individuales un determinado número de votos, que se obtiene dividiendo la cifra total de los votos logrados por cada uno de los integrantes de la correspondiente lista abierta entre el número de candidatos que la formaban hasta un máximo de cuatro, corrigiéndose por defecto las fracciones resultantes. La LOREG no dice nada, en cambio, acerca del posible cómputo de votos con vistas a la elaboración de esa relación en los municipios de menos de 100 habitantes que funcionan en régimen de Concejo Abierto. Pese a la ausencia de previsión legal, la JEC ha aplicado por analogía lo dispuesto para los municipios de 100 a 250 habitantes, aunque en este caso lo que se suma a los votos obtenidos por las diversas entidades políticas son los votos que han obtenido uninominalmente los candidatos a alcalde (acuerdos de la

${ }^{23}$ En el artículo 32 de la LEL se tomaba como base para el reparto de los escaños correspondientes a los partidos judiciales el número de concejales obtenidos por los partidos, coaliciones, federaciones y agrupaciones de electores en la circunscripción. Dicho número servía a efectos de ordenar en columna, de mayor a menor, las formaciones políticas y agrupaciones que obtuvieran concejales y para dividir, después, el total de concejales obtenidos por cada formación o agrupación por uno, dos, tres, etc., hasta un número igual al de los puestos de diputado correspondientes al partido judicial, atribuyendo dichos puestos a las listas con los mayores cocientes. La reforma de este precepto realizada por la Ley Orgánica 6/1983, de 2 de marzo, sustituyó el criterio del número de concejales por el del número de votos obtenidos por las formaciones políticas y las agrupaciones de electores en la circunscripción a efectos de dicho reparto. Ello palió la sobrerrepresentación en la diputación provincial de las zonas rurales menos pobladas, pero con más municipios y mayor número de concejales, sobre las zonas más pobladas, con menos concejales, que propiciaba la redacción primigenia del artículo 32 de la LEL, así como las desigualdades en la consideración del valor del voto popular en la configuración de la corporación que caracterizaron las elecciones locales de 1979, en las que se tomó como base para el reparto de escaños el número de concejales de cada partido judicial. 
fundación

Manuel Giménez Abad

deEstudios Parlamentariosydel Estado Autonómico

JEC de 3 de abril de 1987 y 8 de junio de 1991). No se computan, en cambio, los votos obtenidos por los alcaldes pedáneos de las entidades locales menores, puesto que existiría duplicidad con los computados por el municipio del que dependen ${ }^{24}$.

Una de las singularidades del sistema electoral provincial es que las agrupaciones de electores que se presentan en el partido judicial no pueden acumular o sumar sus resultados municipales, ya sean concejales o número de votos, a efectos de la elaboración de la citada relación de entidades políticas y de la participación en la ulterior distribución de puestos de diputado en las juntas de zona. En sus acuerdos de 17 de febrero, 28 de marzo, 17 de abril y 30 de mayo de 1979, la JEC sostuvo que las agrupaciones de electores que presentaran candidaturas en un municipio eran, por su propia naturaleza, independientes y distintas de las que se presentaran en otros, "no resultando, en consecuencia, acumulable, a efectos de diputados provinciales, el número de concejales obtenidos en distintos municipios por agrupaciones de electores más o menos afines". Y ello porque, "de no ser así, se estaría admitiendo una vía anómala de partidos o entidades políticas". Las sentencias de las audiencias territoriales de Burgos de 12 de mayo de 1979, de Madrid de 23 de mayo de 1979 y de Valladolid de 23 de mayo de 1979 confirmaron el criterio de la JEC y negaron la posibilidad de agrupación de los concejales de las agrupaciones de electores a efectos de elaborar la relación o lista de entidades políticas prevista al artículo 32 de la LEL. Pero la Audiencia Territorial de Barcelona, en sus sentencias de 27 de abril y 10 de mayo de 1979, se pronunció en sentido inverso, admitiendo la posibilidad de agrupación de las listas de concejales independientes a fin de lograr puestos en la diputación provincial. "[...] el acuerdo de la Junta Electoral Provincial, -afirmó la Audiencia Territorial de Cataluña- al excluir en la elección de diputados provinciales la Agrupación de Electores Independientes para la asignación de los escaños correspondientes al partido judicial, vulnera el espíritu y la letra del artículo 32 de la LEL, en cuanto establece en su número primero, inciso primero, que, realizada la proclamación de concejales electos por la junta de zona, se agruparán los concejales de todos los ayuntamientos del partido judicial en función de los partidos, coaliciones, federaciones o agrupaciones de electores en cuyas listas hubieran sido elegidos, formándose una lista de partidos,

${ }^{24}$ E. BELDA PÉREZ-PEDRERO, Los representantes locales en España, Centro de Estudios Políticos y Constitucionales, Madrid, 2000, p. 227. 
coaliciones, federaciones y agrupaciones que hubieran concurrido a las elecciones municipales, pues, de ser admitido el criterio sustentado por la Junta Electoral, quedarían al margen de las elecciones para las diputaciones provinciales las agrupaciones de electores distintas por su propia configuración de los partidos, coaliciones y federaciones" 25 .

Las diferencias interpretativas en torno a la forma de proceder y el convencimiento de que las agrupaciones de electores no representan "una comunidad de puntos de vista ideológicos de política local”, llevó al legislador a incorporar en el artículo 205.1 y 3 de la LOREG la expresión "y de cada una de las agrupaciones de electores" tanto en punto a la elaboración de la relación de las formaciones que han obtenido concejales como de cara a la ulterior distribución de los puestos de diputado ${ }^{26}$. Esta redacción blindó el criterio de la JEC sobre las agrupaciones de electores y ha posibilitado la consolidación de una restrictiva doctrina que se ha mantenido invariable desde entonces, según la cual no es posible la agrupación de los votos obtenidos por distintas agrupaciones de electores que hubieran presentado candidaturas en distintos municipios del mismo partido judicial a los efectos de designación de diputados provinciales; tampoco es posible constituir agrupaciones de electores cuyo ámbito corresponda al de un partido judicial, ya que, a juicio de la JEC, su marco propio en las elecciones locales es el municipal; ni pueden constituir pactos federativos o coaliciones supramunicipales, porque ello constituiría una "vía anómala de creación de partidos o asociaciones políticas al margen de la legislación vigente en la materia" (acuerdos de la JEC de 30 de enero y 5 de junio de 1987, de 18 de noviembre de 1994 y de 2 de junio de 1995, entre otros). $\mathrm{Y}$ en el mismo sentido se pronunció la Audiencia Nacional en su sentencia de 20 de junio de 1987, lo que redunda en beneficio de los partidos políticos allí, precisamente, donde menor es el grado de adscripción política y

\footnotetext{
${ }^{25}$ SAT Cataluña de 27 de abril de 1979, fundamento jurídico 2. Un análisis doctrinal de esta interpretación judicial del artículo 32 de la LEL, en A. EMBID IRUJO, "Una interpretación judicial de la Ley de Elecciones Locales: sobre la posibilidad de unión de listas de concejales independientes a efectos de la atribución de puestos en la Diputación Provincial", Revista Española de Derecho Administrativo, núm. 22, 1979, pp. 437-441.

${ }^{26}$ En este sentido se pronunció el diputado Luis Fajardo Spínola, a la sazón portavoz socialista en el Congreso de los Diputados en la sesión plenaria de 27 de enero de 1983. Diario de Sesiones del Congreso de los Diputados, Pleno, II Legislatura, núm. 10, 1983, pág. 349. La expresión "y de cada una de las agrupaciones de electores" que zanjó la polémica acerca de la relación de candidaturas que debía formar la junta electoral de zona no se introdujo, sin embargo, en la Ley Orgánica 6/1983, de 2 de marzo, de reforma de la LEL, sino dos años más tarde, con ocasión de la aprobación de la LOREG.
} 
mayor alcance pueden tener las iniciativas electorales de grupos de ciudadanos independientes. Debido a ello, alguna doctrina se ha mostrado muy crítica con esta interpretación. En opinión de Biglino Campos, no existen motivos para impedir que las agrupaciones de electores alcancen acuerdos para presentar una candidatura común. "Puede ser que, en el momento de las elecciones municipales, no exista entre ellas una «comunidad de puntos de vista ideológicos de política local». Pero, una vez constituida la asamblea, puede surgir este acuerdo. Menos puntos de contacto existen entre los miembros del Grupo Mixto en el Congreso y el Senado, y en estos casos no solo se les permite, sino que se les obliga a unirse para poder tramitar iniciativas" ${ }^{27}$.

La penalización a las agrupaciones de electores y a las candidaturas estrictamente municipales ha propiciado la formación de partidos y de coaliciones de partidos de independientes de ámbito comarcal y provincial, unas fórmulas que llevarían implícita la estrategia "de sindicar la representación de los independientes y posibilitar el acceso a las diputaciones provinciales" ${ }^{28}$. A diferencia de las agrupaciones de electores, las coaliciones de distintos partidos han tenido un trato más favorable por parte de la JEC y la jurisprudencia. Para computar los votos logrados por los coaligados en la misma coalición basta que los partidos o las federaciones de partidos comuniquen a la junta electoral competente, en el plazo de diez días desde la convocatoria electoral, su pacto de coalición, la denominación de la coalición, las normas por las que se rige y las personas titulares de sus órganos de dirección o coordinación, sin que quepa establecer restricción alguna en ese cómputo en razón de su actividad, de sus promotores o de su domicilio a fin de intentar evitar la suma de los votos obtenidos por las mismas en los distintos partidos judiciales (STC 193/2007, de 10 de septiembre). Para admitir la existencia de una coalición a efectos de cómputo conjunto de los votos obtenidos, no es necesario, sin embargo, que la denominación común comprenda necesariamente la totalidad de los elementos identificadores de la coalición, porque, como el TS ha subrayado, el elemento determinante para

${ }^{27}$ P. BIGLINO CAMPOS, "La reforma de la elección de los miembros de las diputaciones provinciales: mejorar la legitimidad de origen respetando la legitimidad de ejercicio", cit., p. 381. ${ }^{28}$ G. MÁRQUEZ CRUZ, "Las coaliciones políticas en los gobiernos de las diputaciones provinciales de régimen común", Comunicación presentada al IV Congreso de la Asociación Española de Ciencia Política y de la Administración, Granada, 30 de septiembre, 1 y 2 de octubre de 1999 (Área III, Grupo de trabajo 1), ejemplar mecanografiado, pp. 13-14. 
considerarla tal es que en el pacto o acuerdo constitutivo "se ponga de manifiesto la expresa voluntad de los partidos políticos que lo firmaron de constituir una única coalición y comparecer como tal al proceso electoral" (STS 154/2003, de 17 de julio, fundamento de derecho 11). Y, en la misma línea, la JEC ha declarado que "nada impide que una coalición, manteniendo una denominación identificadora común, tenga una denominación o simbología específica en determinados distritos, o que en alguno de estos no se presente candidato de alguno de los partidos integrantes de la coalición" (acuerdos de la JEC de 17 de enero de 1979, de 6 de febrero y 7 de abril de 1995, de 28 de mayo, 15 de julio y 30 de noviembre de 1998 y de 15 de marzo y 20 de abril de 1999, entre otros).

La alteración de los partidos que integran las coaliciones en cada municipio, sí supone, en cambio, la pérdida de la consideración de coaliciones al no tener la misma composición. Cuando un partido político se presenta formando coaliciones electorales distintas en varios municipios de un mismo partido judicial, hay que entender que cada una de estas coaliciones es independiente y distinta de las demás a los efectos del cómputo de los votos y la asignación de puestos de diputados provinciales que prevé el artículo 205 de la LOREG (acuerdos de la JEC de 3 de abril de 1987, de 18 de noviembre de 1994, de 29 de marzo de 1995 y de 9 de octubre de 1997), por lo que no se pueden acumular los votos obtenidos por las candidaturas presentadas independientemente por los partidos coaligados (acuerdos de la JEC de 9 de abril de 1999, de 20 de junio de 2003 y de 3 de mayo de 2007).

\section{LA DISTRIBUCIÓN DE LOS PUESTOS DE DIPUTADO ENTRE LAS FORMACIONES POLÍTICAS Y CADA UNA DE LAS AGRUPACIONES DE ELECTORES ATENDIENDO A LOS VOTOS OBTENIDOS EN EL PROCESO ELECTORAL $A$ QUO}

Elaborada la relación de formaciones políticas y agrupaciones de electores que han obtenido concejales, las juntas electorales de zona distribuyen los puestos de diputado "que corresponden a los partidos políticos, coaliciones, federaciones y a cada una de las agrupaciones de electores" aplicando la regla D'Hondt sobre los votos obtenidos por cada candidatura en las elecciones municipales (art. 205.3 LOREG). En la aplicación de esta regla, no deben 
computarse las fracciones decimales que pudieran obtenerse, ya que el artículo 205.4 de la LOREG prevé qué hacer ante la eventualidad de una coincidencia de cocientes: el puesto en discordia se atribuye a la formación política o agrupación de electores que haya logrado mayor número de votos y, en caso de empate, a aquella que haya obtenido más concejales en el partido judicial y, subsidiariamente, mediante sorteo.

EI TC ha subrayado en varias ocasiones que "la inclusión del pluralismo político como valor jurídico fundamental (art. 1.1 CE) y la consagración constitucional de los partidos políticos como expresión del pluralismo [...] e instrumentos fundamentales para la participación política de los ciudadanos (art. 6 CE) dotan de relevancia jurídica (no sólo política) a la adscripción política de los representantes y hacen que, en consecuencia, esa adscripción no pueda ser ignorada [...] por las normas infraconstitucionales" ${ }^{29}$. De dicha afirmación, formulada a propósito de la composición de los órganos representativos, a prever que los puestos de diputado provincial "corresponden a los partidos políticos, coaliciones, federaciones y a cada agrupación de electores" hay, sin embargo, una gran distancia, porque admitir el alcance de la adscripción partidista no es equiparable a la atribución de los escaños a las propias formaciones políticas. Pero eso ha proclamado el legislador. Y lo mismo ha admitido el TC al afirmar -sin matizaciones o explicaciones complementariasque "el procedimiento de las elecciones a diputados provinciales, por su carácter indirecto y de segundo grado, tiene una lógica interna en la que la atribución de los puestos de diputados corresponde a cada partido o a cada agrupación de electores en función exclusivamente del número de votos obtenidos por estos grupos políticos en cada partido judicial"30.

La literalidad del artículo 205.3 de la LOREG y la referida lógica interna podría llevar a considerar que los escaños pertenecen realmente a los partidos, quienes, a partir de la elección de los diputados provinciales por sus concejales, dispondrían de una suerte de mandato sobre los diputados que les obligaría a actuar en la corporación como depositarios de la representatividad política que reciben y portan. No es, sin embargo, así. El legislador ha incurrido en un exceso al atribuir los escaños a las formaciones políticas y no a las candidaturas, pero no ha pretendido instaurar en las diputaciones provinciales

${ }^{29}$ Por todas, SSTC 32/1985, de 6 de marzo, fundamento jurídico 2, y 141/1990, de 20 de septiembre, fundamento jurídico 6 .

${ }^{30}$ STC 24/1989, de 2 de febrero, fundamento jurídico 4. 
el mandato imperativo bajo la fórmula del "mandato de partido". La representatividad de esos escaños de diputado depende de su reparto entre las candidaturas que, respaldadas por partidos políticos o coaliciones, hayan logrado sumar mayor número de votos en el partido judicial. Lo que la LOREG vincula, por tanto, no son escaños con partidos o coaliciones, sino escaños con candidaturas y votos. Los partidos no canjean los votos recibidos en las elecciones municipales por escaños en la diputación, ni son titulares de los mismos. Los puestos de diputado que las juntas electorales de zona distribuyen en cada circunscripción corresponden a las candidaturas en función del resultado electoral obtenido en las municipales. Y la elección de quienes han de ocupar esos puestos se atribuye a los concejales integrados en ellas, en cuanto compromisarios de su representatividad. Pero la titularidad de los escaños es de los diputados provinciales que resulten proclamados, quienes son plenamente libres para conformar su voluntad en sede representativa y no podrán ser revocados por los partidos que los postularon, ni removidos de su escaño en la diputación por abandonar su militancia o por ser expulsados de dichos partidos. Debido a ello, el acuerdo de la JEC de 26 de noviembre de 1990 declaró inadmisible la retirada de la credencial de diputado provincial por haber solicitado la baja voluntaria en la formación política en cuya candidatura resultó elegido. $\mathrm{Y}$ tiempo después, el TC estimó que la CE "protege a los representantes que optan por abandonar un determinado grupo político y que de dicho abandono no puede en forma alguna derivarse la pérdida del mandato representativo" (STC 185/1993, de 31 de mayo, fundamento jurídico 5$)^{31}$.

\footnotetext{
${ }^{31}$ Partiendo, no obstante, de la premisa de que "existen problemas sin resolver en la doctrina del TC en relación con la titularidad del cargo cuando el concejal abandona voluntariamente a su grupo", las fuerzas políticas signatarias del "Acuerdo sobre un código de conducta política en relación con el transfuguismo en las corporaciones locales", suscrito el 7 de julio de 1998, asumieron el compromiso de estudiar y, en su caso, presentar una iniciativa legislativa de reforma de la LOREG para regular el supuesto de titularidad del cargo cuando el representante local abandone voluntariamente el partido político por el que resultó elegido. Dicho compromiso, sin embargo, no se ha concretado, posiblemente por las dudas de constitucionalidad que suscita. En la doctrina, ha defendido la conveniencia de configurar el abandono voluntario del grupo político como causa de pérdida del escaño, M. A. PRESNO LINERA, Los partidos y las distorsiones jurídicas de la democracia, Ariel, Barcelona, 2000, pág. 158.
} 
V. LA ELECCIÓN, POR LOS CONCEJALES DE CADA ENTIDAD POLÍTICA $Y$ DE ENTRE ELLOS, DE LOS DIPUTADOS PROVINCIALES QUE CORRESPONDEN EN LA CIRCUNSCRIPCIÓN A CADA PARTIDO POLÍTICO, COALICIÓN, FEDERACIÓN O AGRUPACIÓN DE ELECTORES

En los cinco días siguientes a la atribución de los escaños correspondientes a las candidaturas más votadas en cada circunscripción, las juntas electorales de zona convocan por separado "a los concejales de los partidos políticos, coaliciones, federaciones y agrupaciones que hayan obtenido puestos de diputados para que elijan de entre las listas de candidatos avaladas, al menos, por un tercio de dichos concejales" a quienes han de ser proclamados diputados y a tres suplentes para cubrir las eventuales vacantes (art. 206.1 de la LOREG). En la circunscripción no existe, por tanto, un solo colegio electoral, sino tantos colegios de segundo grado como formaciones políticas 0 agrupaciones de electores hayan obtenido en el reparto previo escaños en la diputación. Tantos como permita el tamaño electoral del partido judicial y la fragmentación del voto ciudadano. Y la decisión de cada uno de estos colegios se asume como presupuesto de un acto administrativo esencial: la proclamación de diputados y suplentes por las juntas electorales competentes.

Los concejales de las entidades políticas que han obtenido algún puesto en la diputación no son convocados al acto de votación como representantes de sus municipios, sino en calidad de electos de las formaciones políticas 0 agrupaciones de electores que los incluyeron en sus listas y portando su representatividad. En opinión de alguna doctrina, ello produce una "politización partitocrática de las diputaciones [...] excesiva y detonante en nuestra tradición legislativa local" ${ }^{\prime 2}$. A juicio de otros autores, los concejales se convierten en meros "apoderados de sus partidos" ${ }^{\text {", }}$, razón por la que, atendiendo a razones de economía procesal, podría sustituirse esta elección por la propuesta del representante general de cada candidatura a la junta electoral de zona en la que se indiquen las personas que deben ser proclamadas diputados por dichas

\footnotetext{
${ }^{32}$ L. COSCULLUELA MONTANER y S. MUÑOZ MACHADO, Las elecciones locales, Abella, Madrid, 1979, pág. 328, y L. COSCULLUELA MONTANER, Las elecciones locales, cit., p. 729.

${ }^{33}$ L. MORELL OCAÑA, El régimen local español, cit., p. 774, y M. BARAS y J. BOTELLA, El sistema electoral, Tecnos, Madrid, 1996, p. 152. 
candidaturas ${ }^{34}$. Ambas críticas resultan, sin embargo, excesivas. Los concejales son, en el acto de elección, instrumentos al servicio de la representatividad obtenida por cada candidatura, pero no acuden como meros apoderados de las entidades políticas, ni su intervención en la elección resulta necesariamente formularia. Por regla general, adoptarán el criterio del partido al que pertenezcan y apoyarán con su voto la lista de candidatos a diputado elaborada por sus ejecutivas provinciales, pero, al admitir el legislador la posibilidad de que los concejales "elijan de entre las listas de candidatos avaladas, al menos, por un tercio de dichos concejales a quienes hayan de ser proclamados diputados", no siempre ocurre así, porque, conforme a ello, pueden presentarse varias listas de candidatos pertenecientes a una misma formación política o agrupación entre las que los concejales deberían elegir. Es lo que ha ocurrido en no pocas ocasiones. El predominio de los aparatos de los partidos no es, por tanto, absoluto. Los concejales han concurrido en sus candidaturas, pero la LOREG no les impone disciplina como electores en el colegio electoral.

Como subrayó la STSJ de la Comunidad Valenciana 7548/2003, de 1 de julio, "nos encontramos ante una elección de segundo grado, realizada entre los concejales electos, sin ningún tipo de cortapisa, por lo que mal podría quedar ese derecho de participación política que la ley les da [...] en manos de la decisión del partido o, lo que sería más grave, de su representante. En ese caso sobraría la votación prevista en el artículo 206 de la LOREG y bastaría simplemente con que el representante comunicara a la Junta quienes eran los diputados "designados» por el partido político correspondiente" (fundamento jurídico 3). El legislador, sin embargo, no avala este control partidista sobre sus concejales. Al contrario, posibilita su elección entre listas y les otorga libertad para emitir su voto, una libertad potenciada por la parquedad del artículo 206.1 LOREG, que no especifica la fórmula para elegir a los diputados provinciales en el caso de que existan varias listas, ni si estas son abiertas o cerradas. $\mathrm{Y}$, junto a estas cuestiones, el artículo llamado a regular tan decisiva fase ha dejado otros extremos igualmente significativos sin regular, lo que ha obligado a la JEC y a los tribunales a pronunciarse caso a caso.

${ }^{34}$ I. ASTARLOA HUARTE-MENDICOA, "Comentario al artículo 206", en L. Ma. CAZORLA PRIETO (dir.), Comentarios a la Ley Orgánica del Régimen Electoral General, cit., p. 1795, y B. PENDÁS GARCÍA, "El sistema electoral en las elecciones locales", cit., p. 576. 
fundación

Manuel Giménez Abad

deEstudios Parlamentarios ydelEstado Autonómico

Para empezar, el artículo 206.1 de la LOREG no concreta, como sí hacía en cambio el artículo 33 de la LEL, cuáles son las juntas electorales competentes para convocar a los concejales al acto de elección. Una interpretación sistemática permite, no obstante, atribuir esta tarea a las juntas electorales de zona, puesto que a ellas corresponde, en virtud del artículo 206.2 de la LOREG, proclamar a los diputados provinciales electos en el partido judicial y expedir sus credenciales. Para que la elección sea válida, la LOREG tampoco requiere un determinado quórum o mínimo de participación, lo que planteó la duda acerca del número de concejales que deben acudir a la convocatoria. Como el acto de votación no es una reunión de un órgano colegiado, no procede la aplicación de la legislación básica sobre quórums y mayorías locales de dichos órganos y resulta "suficiente la presencia y votación de cualquiera que sea el número de electores, es decir, concejales de las respectivas listas" (acuerdo de la JEC de 17 de abril de 1979). Los electores deben comparecer, en todo caso, personalmente, sin que quepa ninguna forma de apoderamiento o delegación de voto (acuerdo de la JEC de 10 de julio de 1995). Para la celebración del acto de elección, el artículo 206.1 de la LOREG fija un plazo máximo de cinco días desde la asignación de los puestos de diputado a las formaciones políticas y agrupaciones, pero no señala un mínimo. Suscitada la duda acerca de ese mínimo, la STSJ de Aragón 2179/2003, de 28 de julio, entendió que el plazo de 24 horas entre asignación y elección que había fijado por la junta electoral de zona resultaba suficiente habida cuenta del contenido o finalidad del acto al que se convocaba.

El legislador de la LOREG prevé la elección entre listas avaladas por un tercio de los concejales, lo que "permite no sólo la lista oficial del partido, sino la presentación de cualquier otra que reúna los requisitos legales" (STSJ de la Comunidad Valenciana 7548/2003, de 1 de julio), pero no concreta si los concejales pueden avalar varias listas o solo una. Planteada la duda acerca de la posibilidad de avales múltiples, la JEC determinó que cada edil puede avalar sólo a una candidatura, y si avala varias, se le debe poner de manifiesto para que se pronuncie mediante comparecencia personal sobre el aval que mantiene a fin de conocer inequívocamente su voluntad sin eventuales interferencias partidarias (acuerdo de la JEC de 1 de julio de 1991). La aplicación de este criterio fue, no obstante, recurrida. Pero ante el conflicto existente por la doble manifestación escrita y contradictoria de algunos avalistas, el procedimiento llevado a cabo por la junta electoral, consistente en 
tener solo por válidos aquellos avales ratificados expresa y personalmente, fue ratificado por el TC al ser una interpretación razonable de la LOREG "que se ha aplicado por igual a todas las candidaturas" (ATC de 25 de julio de 1995).

El artículo 206.1 LOREG no precisa si los candidatos a diputados deben ser necesariamente concejales, ni si es posible la elección como diputado de un concejal de otro partido judicial. La lectura del apartado 1 del artículo 208 LOREG, que vincula el cese como diputado provincial a la pérdida de la condición de concejal, y la de su apartado 2, que habla de una nueva elección de diputados "correspondientes al partido judicial" en caso de vacantes, permite extraer una respuesta afirmativa en ambas cuestiones, de suerte que la elección de los diputados provinciales debe hacerse por los concejales de cada formación política en cada circunscripción y necesariamente de entre ellos. Los candidatos incluidos en las listas para la elección de diputados provinciales y suplentes por cada formación política o agrupación de electores deben, además, pertenecer al partido, coalición, federación o agrupación que obtuvo los votos de los que trae causa la asignación de escaños en la diputación. En este sentido se pronunció la STC 24/1989, de 2 de febrero, confirmando la SAT de Valladolid de 9 de julio de 1987, que había rechazado que un concejal electo por una agrupación independiente figurara como suplente en una de las candidaturas presentadas por los concejales del Partido Popular (PP) para cubrir los escaños que le correspondían en su circunscripción. Y ello, porque, a juicio del TC, "la posibilidad contraria, que permitiría [...] incluir en las listas para la elección de diputados provinciales a concejales que hubieran obtenido el acta por otros partidos o agrupaciones, o incluso a ciudadanos que no ostentaran la condición de concejal, pugnaría con la lógica interna del sistema diseñado por el legislador, ciertamente con carácter indirecto y de segundo grado, pero en el que los puestos de diputados provinciales están en función del número de votos obtenido por cada partido y no del número de concejales, como si éstos fueran unos compromisarios absolutamente independientes y desvinculados del derecho de sufragio activo del que traen causa" (fundamento jurídico 4). Conforme a dicha interpretación, el abandono del grupo de concejales correspondiente a la formación política que presenta la lista de candidatos a diputados ha de considerarse como causa de pérdida de la condición de candidato a diputado provincial integrado en dicha lista (acuerdo de 15 de octubre de 2001). 
fundación

Manuel Giménez Abad

deEstudios Parlamentarios ydelEstado Autonómico

Las listas de candidatos deben ser completas, incluyendo tantos candidatos como diputados provinciales corresponda elegir al grupo de concejales de que se trate, más tres suplentes para cubrir por su orden las eventuales vacantes. El incumplimiento de este requisito, así como del de la adscripción política de los concejales, puede ser, no obstante, subsanado, como subrayó la STC 24/1989, de 28 de febrero, por considerar que las disposiciones generales del título I de la LOREG, y en particular su artículo 47.2, son aplicables a todos los procedimientos electorales, incluido el indirecto de las diputaciones provinciales. En el supuesto, por tanto, de incluirse en una lista de candidatos un concejal que no pertenece a la formación política o agrupación de electores a la que corresponda el escaño o de presentarse una lista incompleta, las juntas electorales de zona deben arbitrar un plazo de subsanación de las irregularidades, cuya duración fijarán discrecionalmente dentro de las limitaciones que impone el calendario electoral, porque de lo contrario se vulneraría el derecho fundamental al acceso a un cargo público en condiciones de igualdad (art. 23.2 de la CE) de los candidatos de la lista presentada que sí reúnen las condiciones personales legalmente exigibles (fundamentos jurídicos 5 y 6 de la STC 24/1989).

El incompleto artículo 206.1 de la LOREG tampoco concreta si las listas deben ser abiertas o cerradas, ni la fórmula electoral aplicable en el supuesto de que concurran varias listas válidamente presentadas por los concejales de una misma entidad política. Según el criterio de la JEC, las listas de candidatos a las diputaciones provinciales deben ser cerradas y bloqueadas $\mathrm{y}$, de concurrir varias, la asignación de los puestos de diputado debe realizarse mediante la aplicación supletoria de la regla D'Hondt prevista en el artículo 163 de la LOREG (acuerdos de la JEC de 1 de julio de 1991 y de 3 de mayo de 1999). La cuestión, sin embargo, no ha sido en absoluto pacífica. Aplicado dicho criterio por la Junta Electoral de Zona de Almería, el representante legal del PP interpuso recurso contencioso-administrativo por entender que la fórmula electoral a aplicar debía ser mayoritaria entre listas cerradas, de suerte que la lista más votada copara todos los puestos de diputado provincial que le habían sido asignados en el partido judicial de Almería. La STSJ de Andalucía de 31 de julio de 1991 ordenó a la Junta de Zona convocar nuevamente a los concejales populares para que eligieran a los diputados "mediante votación de los candidatos presentados en ambas listas, designando a quienes más votos obtengan", esto es, se pronunció a favor de la apertura de las listas. 
Radicalmente disconforme con este criterio, el PP recurrió en amparo ante el TC, quien, en Sentencia 174/1991, de 16 de septiembre, consideró la decisión judicial impugnada acorde con el artículo 23.2 de la CE y con suficiente apoyo en el tenor literal del artículo 206.1 de la LOREG.

"El artículo 206.1 de la LOREG -afirmó el TC- no regula de forma completa el supuesto en el que, una vez asignado el número de diputados provinciales que corresponden a cada formación política, los concejales pertenecientes a alguna de esas formaciones presenten más de una lista de candidatos para ocupar los puestos [...], pero sí hay en el citado artículo 206 de la LOREG elementos que permiten su interpretación para resolver el modo de asignar dichos puestos [...] ante la hipótesis señalada. La Sentencia recurrida ha partido de esos elementos interpretativos, en particular, de la afirmación legal de que los diputados deben elegirse «de entre las listas de candidatos»; esta expresión ha sido interpretada en el sentido de que se trata de listas abiertas, en un criterio cuya constitucionalidad, tal como ha recordado el Ministerio Fiscal, se encontraba ya apuntada por la STC 24/1989 (fundamento jurídico 5). Pero, al margen de ello, la interpretación tiene apoyo en el tenor literal del precepto, que, como se ha visto, se refiere a elección no de listas sino «de entre las listas»; en consecuencia, el criterio seguido no resulta en absoluto arbitrario o injustificado, asegurando, además, la igualdad de condiciones para el acceso a los puestos de diputados provinciales a todos los candidatos que concurran a la elección y que cumplan los requisitos legales para ello, tal como exige el artículo 23.2 de la C.E”35. No en vano, como percibió el partido recurrente, dicha fórmula concede a los electores un amplio margen para configurar el resultado.

La STC 174/1991 no excluyó, sin embargo, que pudieran existir otras interpretaciones distintas del precepto igualmente conformes con la CE, ni que las juntas electorales establecieran un procedimiento de elección alternativo, que sería admisible siempre que no incurriera en arbitrariedad y estuviera justificado Por ello, la JEC ha mantenido su doctrina y, en respuesta a la consulta formulada por el secretario técnico de la Federación Aragonesa de Municipios y Provincias, reiteró que, en caso de concurrencia de diversas listas de una misma entidad política, "la asignación de los puestos de diputados provinciales se realizará mediante la aplicación supletoria de lo dispuesto en el

${ }^{35}$ STC 174/1991, de 16 de septiembre, fundamento jurídico 4. 
artículo 163 de la LOREG" (acuerdo de la JEC de 3 de mayo de 1999). Y en el mismo sentido se ha pronunciado el TSJ de la Comunidad Valenciana, en cuya Sentencia 7548/2003, de 1 de julio, consideró que "es más acorde el sistema de listas cerradas con el que prevé la norma, pues en caso contrario no prevería la existencia de suplentes, que se suponen han de sustituir a los titulares de la lista, y no se prevé la llamada a los más votados" (fundamento de derecho 4).

Concluida la elección, los cuerpos electorales de concejales se disuelven y sólo cabe convocarlos de nuevo, exartículo 208 de la LOREG, en el supuesto de que las vacantes de diputado por fallecimiento, renuncia o pérdida de la condición de concejal no puedan cubrirse por los suplentes. Las juntas electorales de zona proclaman los diputados electos y los suplentes en cada circunscripción, expiden las credenciales correspondientes y remiten a la junta provincial y a la diputación certificaciones de los diputados electos en el partido judicial (art. 206.2 de la LOREG). Con ello concluye el procedimiento electoral provincial y se abre el proceso de constitución de la diputación provincial, en cuya sesión constitutiva los diputados han de elegir de entre ellos al presidente. A partir de ese momento, todos los miembros de la diputación reunidos reglamentariamente son representantes de la comunidad provincial y poseen todas las garantías constitucionales de los cargos públicos representativos, pero no merced a su elección directa por los ciudadanos, como el TC había sostenido con vocación general en sus primeros pronunciamientos sobre representantes locales, sino por la naturaleza representativa atribuida por la CE al órgano del que forman parte. $Y$ debido, precisamente, a la singularidad del sistema electoral de segundo grado de las diputaciones provinciales, el TC se vio en la obligación de reconsiderar su aproximación jurisprudencial al concepto de representación política, lo que evidencia el alcance que ha llegado a tener este sistema electoral en la delimitación de una cuestión constitucional tan esencial.

El TC construyó su primera aproximación a la noción de cargo público representativo sobre la base casi autónoma del artículo 23 de la CE, y a raíz de varios recursos de amparo interpuestos contra la aplicación del artículo 11.7 de la LEL, que preveía el cese de los representantes municipales a causa de su expulsión del partido político con el que concurrieron a las elecciones. Condicionado por los actos impugnados, el TC vinculó la representación 
política a la elección mediante sufragio universal. "Es obvio -afirmó en su STC 10/1983, de 21 de febrero (fundamento jurídico 2)- que, pese a la identidad de legitimación de todos los titulares de cargos públicos, sólo se denominan representantes aquellos cuya designación resulta directamente de la elección popular, esto es, aquellos cuya legitimación resulta inmediatamente de la elección de los ciudadanos" ${ }^{36}$. Lo decisivo para ser representante pasó a ser, a la sazón, la relación creada por la elección, cuya inmediatez permitía presumir la "unidad de voluntades" entre representante y representados sobre la que se consideró asentada la idea de representación política democrática. El problema es que, con esta conceptualización de la representación, los diputados provinciales no serían cargos representativos. Al resultar elegidos por los concejales integrados en candidaturas determinadas, y no por los ciudadanos, la relación que permite la imputación de voluntades propia del concepto de representación reseñado habría desaparecido. Los diputados serían cargos públicos legítimos, por supuesto, pero, sin elección directa, carecerían de las garantías que acompañan al derecho fundamental reflejo derivado del artículo 23.2 CE.

Llegado, sin embargo, el momento de pronunciarse sobre la condición representativa de los diputados provinciales a resultas de un recurso de amparo, el TC no dudó en otorgar el amparo requerido, adoptando ad casum una idea distinta de representación. Frente a la representación como relación, optó por la representación como atribución normativa; una atribución que el ordenamiento reconoce a un órgano del Estado y que se distingue conceptualmente de la elección. La elección legitima democráticamente el mandato, pero no lo determina, porque la representación existe independientemente de la forma de elección y puede llegar a disociarse de ella $^{37}$. Las diputaciones, vino a afirmar en la STC 163/1991, de 18 de julio, son órganos de naturaleza representativa ex artículo 141.1 de la CE. Los diputados provinciales carecen de la relación inmediata con el cuerpo electoral de los parlamentarios y concejales, pero también son cargos públicos representativos por su condición de miembros de dichos órganos, a los que se atribuye esa

\footnotetext{
${ }_{37}^{36}$ En el mismo sentido, la STC 30/1983, de 26 de abril, y en el ATC 6/1984, de 11 de enero.

${ }^{37}$ Sobre la distinción conceptual entre representación y elección y, no obstante, la importancia del fundamento electivo de la representación, G. SARTORI, "Representación", en Elementos de teoría política, Alianza, Madrid, 1992, pp. 231-233.
} 
naturaleza ${ }^{38}$. Por eso gozan de los derechos implícitos contenidos en el artículo 23.2 CE, aunque entre ellos y los ciudadanos no medie una genuina relación representativa. Y por eso son representantes de la provincia en el seno de la institución representativa reglamentariamente convocada, sin que su elección indirecta limite o menoscabe esa condición ${ }^{39}$.

38 " [...] la violación del derecho a acceder y ejercer la función y el cargo representativo afecta también indirectamente al cuerpo electoral, cuya voluntad representa, sobre todo cuando, como en el presente caso, se trata de una corporación provincial cuya naturaleza representativa aparece definida por la propia Constitución". STC 163/1991, de 18 de julio, fundamento jurídico 3 .

${ }^{39}$ Sobre esta cuestión, C. GARRIDO LÓPEZ, "El diputado provincial como representante", Revista Española de Derecho Constitucional, núm. 60, 2000, pp. 124-138. 